\title{
Exploring the Textual Variations of Metaphors in Terms of Rank Dimension and Their Discoursal Values across Different Text-types
}

\author{
Abbassi Bonabi Mina \\ Payam-e-noor University, Iran \\ Email: mina_abbasi89@yahoo.com \\ Hemmati Fatemeh \\ Payam-e-Noor University, Iran \\ Email: hematitefl@gmail.com
}

\begin{abstract}
Working within the framework of Systemic- Functional Grammar and defining metaphorical expressions as a textual / intertextual strategy, bringing `guest images` from other universes of discourse to the semantic realm of texts, and also believing that the occurrence of metaphoric expressions in texts is meaningful and motivated, in this study we looked at the textual variations in terms of rank dimension across three different genres of scientific, literary and journalistic texts. We found out that these different genres cannot be differentiated from each other in terms of presence or absence of this strategy. Indeed metaphorical expressions appear in all text types. We speculate that different dimensions of meaning are added to the text through use of this strategy across different genres. The findings of this study revealed that this strategy contributes to ideational function of the texts in the scientific text type. Our study revealed that in the literary and journalistic texts, this strategy contributes to 'textual function' as well as 'ideational function' of the texts. In journalistic texts, the main function of metaphors is to contribute to the 'indirectness' of the texts. In literature, metaphoric wordings are 'thematically motivated', reinforcing the theme of the texts. For this purpose 14 different texts from different text-types are selected to be analyzed in term of the use of metaphorical expressions.
\end{abstract}

Index Terms-metaphor / metaphoric expression, intertextuality, variations in rank dimension, textual function, ideational function, indirectness, thematically motivated element

\section{INTRODUCTION}

Traditionally metaphor is thought to be a literary device or a special pattern of language which mostly appears in literary texts. Stylisticians tend to characterize metaphor as a property of literature because it is in literature that metaphor catches our attention mostly. The traditional view states that "metaphor is an ornamental aspect of speech and thought" (Tendahl, M. \& Gibbes, R.B.2008 p: 1823). They further argue:

"A traditional belief among many scholars is that metaphorical meaning is created de novo, and does not reflect preexisting aspects of how people ordinarily conceptualize ideas and events in terms of pervasive metaphorical schemes. But in the past 25 years, various linguists, philosophers, and psychologists have embraced the alternative possibility that metaphor is fundamental to language, thought, and experience" (Tendahl,M. \& Gibbes, R.B. 2008 P: 1825).

Working within the framework offered by the cognitive approach to the study of metaphor and adopting Systemic Functional Grammar as a framework of text analysis, we assume that the presence of metaphor like any other textual strategies is neither sufficient nor necessary condition of literariness. According to new trends in linguistics and genre analysis, the difference between literature and non- literature is not the result of the presence of special linguistic devices in literature. Indeed what distinguishes different genres from each other in general and literature from nonliterature in particular rather than being the result of presence or absence of some particular and specific linguistic ingredients, is established through the value and function of the specific linguistic devices (Lotfipour;1992). That is to say it is not just the textual strategies or linguistic ingredients which differentiate different text- types from each other (Lotfipour; 2006). Rather it is the effect and underlying discoursal functions of the textual strategies which draw lines between different genres (Lotfipour \&Abbasi 2000-2001). So we do not consider metaphor merely as a literary device. Rather we consider it as a textual/intertextual strategy which can be realized and actualized in any text contributing to fulfill different functions in difference genres. As it is stated by Tendahl, M. \& Gibbes, R.B (2008) metaphor "is not merely a figure of speech, but a specific mental mapping and a form of neural coactivations that influences a good deal of how people think, reason, and imagine in everyday life" (P:1825). In the following section we present some views on the different functions of metaphor based on previous studies.

\section{A. Metaphor and Texture}


Textuality or texture refers to text- forming devices which distinguish text from non-text (Halliday and Hasan; 1976). The texture- forming resources are textual and formal manifestation of textual function. As Halliday (1973) mentions it is through textual function that a text makes links with itself and its situation. It is argued that textual function is concerned with the "semiotic reality" through which 'ideational meaning' and 'interpersonal meaning' are realized as text (Martin: 1995, p: 9). As it was mentioned above, the textual meaning embodies texture or text forming devices. Among textual feature contributing to texture, Halliday and Hasan (1976-1990) refer to cohesion. They argue that cohesion is manifestation of underlying 'topical unity'- coherence- and is realized at lexico-grammatical level through cohesive devices (Halliday and Hasan 1990).

In a study, entitled metaphor as a textual strategy, Mei-zhen (1999) showed that metaphor is a textual strategy and a text - building device which contributes to texture of the text. He argued that metaphor can function as a cohesive device, contributing to textuality of the text.

\section{B. Metaphor and Ideational Function of Language}

Within the framework of Halliday's Systemic Functional Grammar, it is argued that one of the most important functions of language is 'ideational function' or 'ideational meaning' (Halliday; 1985). Ideational meaning is related to relationship between language and outside realities and experiences. Halliday, defining language as a product of social process (Halliday; 1978) believes that language performs at once a 'dual function' as a means of action and as a means of reflection (Halliday; 1985). Ideational meaning is related to the function of language as a means of reflection; reflection of outside realities and experiences. However, as it is mentioned by Threadgold (1987), the function of language is not limited to reflect outside realities, but language as a reality constructing and reality- changing semiotic process contributes to formation of new meanings and "restructuring of the semantic system" within a culture (Threadgold; 1987; P: 345). In this regard language is a means of action. The focus of this section is on the relationship between ideational meaning of language (as a means of reflection) and the value of metaphoric uses of language to fulfill this function.

Cognitive linguists claim that language users employ metaphors in their discourses in other to convey new ideas and abstract things through familiar and more concrete object and entities (see Lakoff; 1991). That is to say by expressing unknown and abstract things through more concrete entities, they reflect their experiences and intentions to others. Since metaphor is commonly used to express new ideas through the knowns, it is argued that one of the most important functions of metaphor is 'world- disclosing' function (Debatin; 1995) through which we extend our understanding of the world and outside realities.

\section{Metaphor and Its Effect on Cognition}

It is said that metaphor like other types of figurative language is a special pattern of language structure which is imposed upon ordinary literal use of language. Most philosophers have generally argued that figurative language, metaphor included, involves tricks or play on the literal (Tim Rohrer; 1995). So it is inferred that understanding metaphors takes longer time. But in a research conducted by Rohrer (1995), it is proved that understanding metaphor takes no longer time provided there is sufficient context. He argues that the bulk of our metaphoric processing is automatic and only some metaphors require attentional processing to be understood (Rohrer; 1995).

In this regard George Lakoff (1991) argues that the use of metaphor is common place and inescapable. Abstraction and enormously complex situations which are difficult to understand are routinely processed via metaphor. Indeed there is an extensive, and mostly unconscious, system of metaphor that we use automatically and unreflectively to understand complexities and abstractions. Put in other words, we can say that the use of metaphoric expressions promotes our understanding in most cases. Mei- zhen (1991) also demonstrated that metaphor has cognitive effect and helps the language users to understand and comprehend new ideas better. It is argued by cognitive linguists that the mapping helps us to learn what is new, unknown or unfamiliar (Liao- Mei- zhen: 1999).

So not only do we use metaphor in our uses of language unconsciously, the process of cognition of it also takes place, in most cases without special attention. Indeed, metaphoric uses of language rather than being blocks in our understanding, in most cases, they promote our comprehension (Tim Rohrer; 1995).

It is demonstrated that unlike old metaphors, some new metaphors take longer time to be understood (see Tim Rohrer; 1995). This may contributes to literariness of literature- texts, because in literary texts we encounter lots of new metaphor. This prolonged search for meaning contributes to literariness of texts (see Lotfipour; 1989).

\section{Metaphor and Politics}

Regarding language as a reality constructing and reality-changing phenomenon, critical linguists believe that language is not an indifferent mirror of the outside objective realities (see Birch; 1990). Following this line of thinking critical linguists believe that language is not an indifferent mirror of presenting social realities rather outside realities and meaning are contracted through use of language. Butt (1988) argues that language is not a mirror of preverbal reality. According to Ryan (1991) the kind of language people use determines the way they see themselves and the way they see realities.

Defining text as the unit of language, Halliday views text as a semantic unit, a process of meaning in a continuous interaction with other semiotic system of a society (Halliday; 1978). It is argued that the relationship between language 
and society is not unidirectional; rather the relationship is bi-directional (see Birch, 1990 \& Fairclough, 1990). That is to say language reflects the meaning and realities of the society and at the same time influences and gives direction to the social realities (Fairclough; 2010). Text, in Halliday`s view is the actualization of a higher order semiotic system which in his view constitutes the reality of culture (Halliday: 1978). Culture can be considered as a network of interrelated potential semiotic system i.e. a system of potential behavior or a system of what one can do (ibid). In the process of verbal transactions, a text as the unit of communication (Lotfipour; 1993) would actualize some meaning potentially available in the semiotic system of the society (Halliday; 1978). But it is argued by critical linguists that meanings potentially available in the culture do not have the same chance to be actualized and realized through using of language. It is the function of power system or dominant ideologies which put in foreground some meanings while suppressing other meaning to be actualized through language (see Fairclough; 2010). That is to say the function of dominant ideologies in the society is to establish recurrent pattern of semantic choices in a culture and determine the culture`s "characteristic ways of meaning" out of a large amounts of potential semantic choices within a society (Threadgold; 1987).

Accepting that language has grown dramatically in term of the uses it is required to serve (Fairclough; 1990), critical linguists claim that the grammatical system of language is closely related to social needs - ideological needs included that language is required to serve (Fairclough; 1990). So studying textual strategies employed in a text reveals a lot of facts about underlying social conventions and power systems existing in the society (ibid).

We argue that the use of metaphors determine our world- view (see Lakoff; 1991). Metaphor as textual / intertextual strategy is used mostly and skillfully in political texts to determine and direct the way people think and the way they behave. As Lakoff (1991) argues there is a widespread, relatively fixed set of metaphors that structure how human beings think.

In a paper entitled "Metaphor and War: The Metaphor System used to Justify War in the Gulf" (part a), George Lakoff (1991) argues that one of the metaphors used in politics is: "war as medicine". He says that there is a common metaphor in which military control by the enemy is seen as a cancer that can spread. In this metaphor, military "operations" are seen as hygienic, to "clean out" enemy fortifications.

In another paper entitled "Metaphor, Morality, and Politics" (1995), George Lakoff argues that morality, being an abstract notion, in most cases is determined by metaphor we use. Lakoff (1995), as an example for the metaphor used to express morality, mentions to "Being Good is being Upright" (Lakoff; 1995). Examples for this metaphor "include sentences like: He's an upstanding citizen, He's on the up-and up (ibid). Lakoff (1995), as another example of metaphor for morality, mentions to "morality is strength". He argues people are not simply born strong. Moral strength must be built. Just as in building physical strength, where self-discipline and self-denial (no pain, no gain) are crucial. Therefore moral strength is also built through self-discipline and self-denial (Lakoff, 1995). From this example we understand how abstract things like morality can be expressed by using metaphoric expressions.

Lakoff (1995), as an example of metaphor used in politics, mentions to: "the Nation -as- Family Metaphor". In this metaphor the nation is seen as a family, the government as a parent and the citizen as children. By using metaphors like the metaphors mentioned above, those who are in power try to impose their intentions and wishes. For example by using "the nation -as- family" metaphor, they say that government is wiser than the nation (government is parent, while the nation is a child) and most of the works of government are justified. So metaphors play a very important role in maintenance of institutions of power in the society. Therefore, we agree with critical linguists in regarding language as an instrument of repression (see Fairclough, 1990).

But as Fairclough (1990) claims it is in the capacity of human beings to change what human beings have created. That is to say by 'consciousness-raising' processes, critical linguists can help people to use language in a way which bring them freedom (ibid). It is believed that language is not only a 'reality- constructing' process, but also it is a 'reality- changing' phenomenon which can and should be used in the process of "emancipation" (Fairclough; 1990).

\section{E. Metaphor \& Intertextuality}

The notion of 'intertextuality` was developed by Julia Kristeva in 1967 in her seminal work on intertextuality Word, dialogue and novel (Still \& Worton, 1990; P: 1) in the intellectual context of Cultural Revolution of 1960, in France to revolutionalize not only structuralism but cultural politics in general (see Pfister; 1991).

The notion of intertextuality can, in essence, be traced back to Bakhtin who considers the dialogic concept of language as fundamental (cf. Still \& Worton; 1990). Unlike Bakhtin who claimed that some texts are monologic and dialogic while others are dialogic, Kristeva believed that both of monologic and dialogic language can be found in any text (Still \&Worton; 1990). For Kristeva every text is as intertext governed by dialogism (see Still \&Worton; 1990\& Pfister; 1991).

According to the theory of intertextuality, text is not a self-coherent and self-contained entity (Birch; 1990). Text being a semantic unit is not a well-defined object. Text, unlike clause which is a lexico-grammatical entity with the clear-cut beginning and ending, is an abstract and semantic entity which does not have the established boundaries (see Birch; 1990). A text, as Halliday mentions (1987) is not something that has a beginning and the ending. Derrida expresses a similar view (c.f. Birch; 1991; P: 9). A "text for Derrida is a complex network of unfinished meaning that its openings and ending can never be found" (Birch; 1990). He, however, argues, "[t]here are of course edges and 
borders to a text" but "these are not set by the text or the writer" (Birch; 1990 P: 11). Rather the borders and boundaries of the text are established by institutional practices (ibid).

Text, as a semantic process, rather than carrying the meaning, is assumed to provide only a 'meeting ground between the discourse processes of the text producer and text receiver (see Candlin \& Lotfipour; 1983). The 'textual indices ' used in a text are the manifestation of the writer's or the speaker's discoursal strategies and are motivated by many socio-psycholinguistic factors determined by 'characteristic pattern of meaning' recurrent in the society (see Candlin and Lotfipour; 1982 \& Birch, 1990). The `textual indices` also act as activators of the readers discourse process (Candlin\& Lotfipour; 1982). The receiver of the text by relating textual indices to the belief systems, conventions, knowledge frame and characteristic ways of meaning 'recurrent in the society' sets his own discourse process in motion for the possible negotiation of the writers messages ( see Candlin and Lotfipour; 1982). Every text is by its nature an intertext because the processes which lead to its production and comprehension are necessarily intertextual and intersemiotic processes (see Birch; 1990).

\section{Modes of Intertextuality}

Defining intertextuality as the property of discourse rather than text, and characterizing intertextual strategies as discoursal strategies, we speculate that in textualization process, the intertextual strategies can be realized in different modes (see Lotfipour \& Abbasi; 2000). From structural point of view the modes of intertextuality can be divided into two groups: 1) visible 2) invisible. Structurally visible modes have usually definite pretexts. (By pretext we mean the text from which the intertextual element is taken). Questions are instances of the visible mode of intertextuality. (This mode of intertextuality was already investigated by Loftipour \& Abbasi; 2000 \& 2001). It seems to us that thematic structure is as instance of invisible mode of intertextuality. (By structural invisible intertextuality element, we mean those intertextual elements which do not have any definite pretexts.)

\section{Metaphor as an Intertextual Strategy}

In our characterization, metaphors are also invisible intertextual elements because the producer of the text by using metaphor brings in "guest images" to the universe of his text. According to Goalty (1997) metaphor can be defined as a unit of discourse used to refer to an object, concept, process, quality, relationship or word to which it does not conventionally refer (c.f. Dastjerdi; 2000). By metaphor Halliday (1985) means. 'Non-literal use of words' "a word used for something resembling that which it usually refer to" (p: 319). According to Halliday (1985) the words flood and poured in, in the following sentences are examples of metaphoric use of language:

\section{A flood of protests poured in following announcement.}

Halliday (1985) argues that "most instances of metaphoric wording involve transfer from a concrete to an abstract sense and one large class of these is from material to mental process, as in “it escapes me", I haven't grasped it, I don't follow" (Halliday; 1985 p: 319).

Metaphor is one way of using language indirectly. That is to say in the metaphoric use of language there is always a clash between what is said and what is meant. The speaker says something but he means something different and more than what he actually says. It is the concern of this study to explore the underlying motivation(s) of using this strategy across different genres. As it was mentioned above, metaphor can be characterized as a mode of intertextual strategy because when we use metaphoric wordings in a text, we bring images from other semiotic systems to the universe of our text and by so doing we establish intertextual connection between the two universes.

\section{Methodology \& Design}

\section{A. Data}

This study is concerned with the variations in the textualization of metaphor as an intertextual strategy and its discoursal functions across different genres. For this purpose we adopted a corpus linguistic approach and selected a total number of 14 texts to be analyzed. These texts are chosen from three different genres: literary texts, scientific texts $\&$ journalistic texts. Text $\neq 1$ is taken from Cook $\&$ Newson (1995). Text $\neq 2 \& 3$ are taken from Kingsbury \& Wangner (1990). Text $\neq 4$ is taken from Berridge \& Winkielman (2003), text $\neq 5$ is taken from Tallis (2003), text $\neq 6$ is taken from Jenkins \& Ambrosini (2002. Texts $\neq 7$ to 12 are literary texts. Text $\neq 7$ is a piece of a novel written by Jane Austen: Pride \&Prejudice. Texts $\neq 8.9 \& 10$ are poetry. Text $\neq 11$ is a piece of Antigone written by Sophocles. Text $\neq 12$ is a short story written by Nathaniel Hawthorne. Text $\neq 13 \& 14$ are journalistic articles taken from Time and Newsweek (1990-1995). The dimension of textual variation focused upon is variations in rank dimension.

\section{B. Variations in Rank Dimension}

We speculated that in any text metaphorical wordings can be actualized in different ranks. By rank it is meant what is normally meant in the systemic linguistics as the hierarchical ranks of language structure as clause, group, word, etc (Lotfipour: 1997). It is the concern of this study to look at the variations of textualization of metaphorical wordings, in terms of rank dimension and their underlying discoursal values both within a text type and across different genres.

\section{Results of Data Analysis}

Having analyzed our selected texts in terms of variations in rank dimension, we summarized the results in the following table and graphs. 
TABLE $\neq 1$

THE FREQUENCY OF OCCURRENCE OF METAPHORICAL EXPRESSIONS IN SCIENTIFIC, LITERARY AND JOURNALISTIC GENRES.

\begin{tabular}{|c|c|c|c|c|c|c|c|c|}
\hline \multicolumn{3}{|c|}{ Scientific text-type } & \multicolumn{3}{|l|}{ Literary text-type } & \multicolumn{3}{|c|}{ Journalistic text-type } \\
\hline Rank & $\mathrm{F}$ & $\mathrm{P} \%$ & Rank & $\mathrm{F}$ & $\mathrm{P} \%$ & Rank & $\mathrm{F}$ & $\mathrm{P} \%$ \\
\hline Text & 0 & 0 & Text & 0 & 0 & Text & 0 & 0 \\
\hline Clause-complex & 0 & 0 & Clause-complex & 18 & 22.5 & Clause-complex & 3 & 11 \\
\hline Clause & 0 & 0 & Clause & 0 & 0 & Clause & & \\
\hline Pre.P & 0 & 0 & Pre.P & 4 & 5 & Pre.P & & \\
\hline adj.p & 0 & 0 & adj.p & 3 & 4 & adj.p & & \\
\hline adv.p & 0 & 0 & adv.p & 0 & 0 & adv.p & 2 & 7 \\
\hline VP & 17 & 11 & VP & 9 & 11 & VP & 4 & 15 \\
\hline $\mathrm{NP}$ & 16 & 10 & NP & 12 & 15 & $\mathrm{NP}$ & 4 & 15 \\
\hline \multirow{2}{*}{ Individual words } & 125 & 79 & \multirow[t]{2}{*}{ Individual words } & 34 & 42.5 & \multirow[t]{2}{*}{ Individual words } & 14 & 52 \\
\hline & $\sum_{\mathrm{N}=158}$ & 100 & & $\sum_{F=80}$ & 100 & & $\sum_{\mathrm{N}=27}$ & 100 \\
\hline
\end{tabular}

For calculating P\% we use:

$$
\mathrm{P} \%=\frac{f \times 10}{N}
$$

NP stands for noun phrase

VP stands for verb phrase

Adj stands for adjective phrase

Pre.p stands for prepositional phrase

The following graph (graph \# 1) illustrates the variation of frequency of metaphorical expressions in terms of their rank within the scientific text-type, summarizing the data gained from our analysis of scientific texts \& data presented in table\# 1

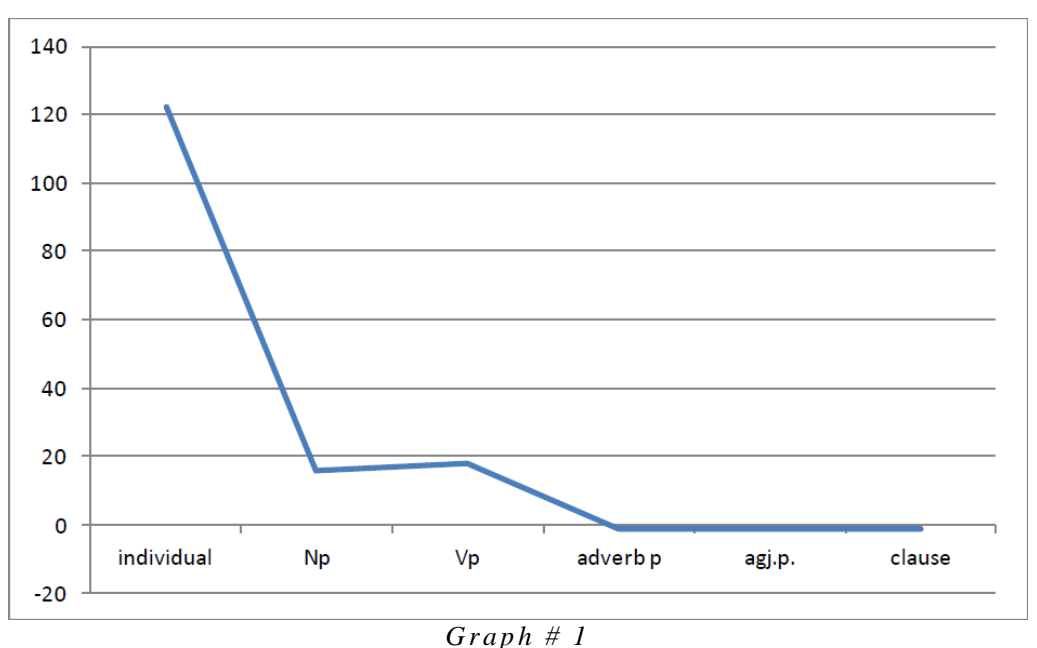

The graph \# 2 illustrates the variation of frequency of textual realization of metaphors in literary text-type in terms of their rank, summarizing the data gained from our text analysis \& the data represented in the table\#1

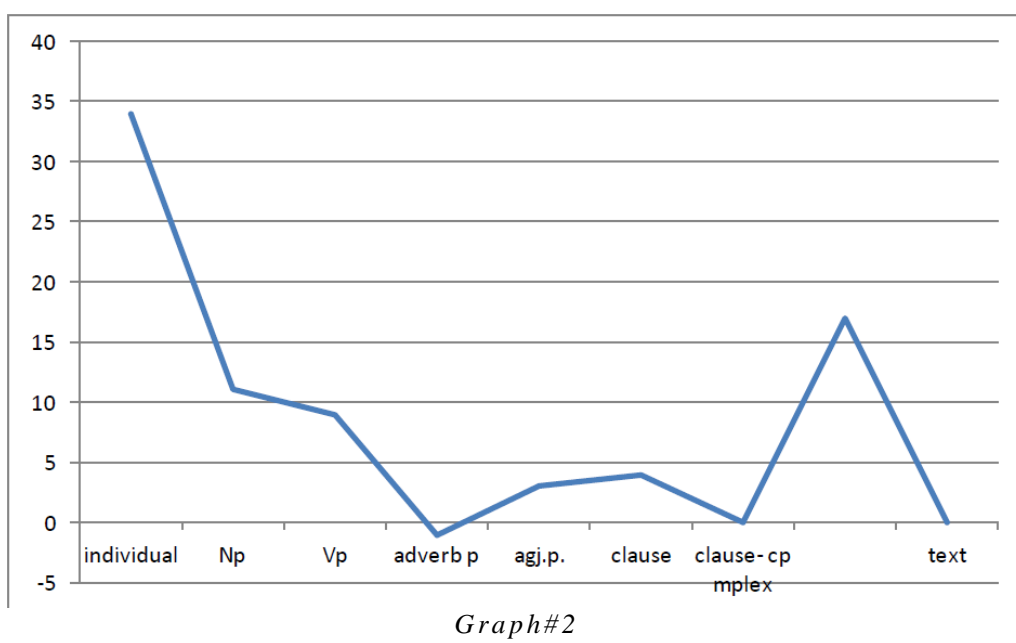


The graph \# 3 represents the variations of frequency of textual realization of metaphor in terms of their rank in journalistic text-type, summarizing the data gained from our text analysis \& the data represented in the table\#1

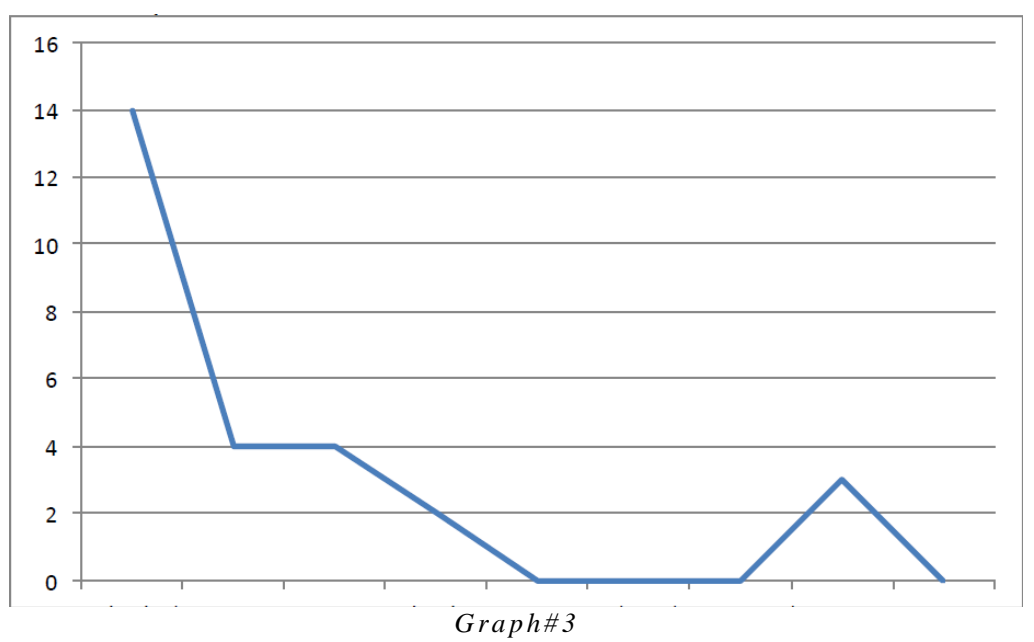

\section{INTERPRETATION OF THE RESULTS OF DATA ANALYSIS}

\section{A. Individual Word Metaphors in Scientific, Literary, and Journalistic Text-types}

As illustrated in table.1 and graphs 1-3, individual word (single word) metaphors occupy the highest level of frequency of occurrence in all of our analyzed text-types. In scientific text-types, the incidence of frequency of occurrence of individual word metaphors is $79 \%$, in literature text-type the incidence of occurrence is $42.5 \%$ and in journalistic text-type, the frequency of occurrence is $52 \%$. On the basis of our data analysis we find out that, there is no significant difference between these three different genres regarding the frequency of occurrence of single word metaphors. This finding supports our speculation that different genres cannot be differentiated from each other with respect to presence or absence of specific mode of textual strategy. Rather it is the value and function of specific textual elements which draw line between different genres. In data analysis procedure, we noticed that, in scientific text-type out of total number of 125 single word metaphors, only 28 cases are marked. By marked metaphorical expression we mean those instances of metaphors whose literal or congruent equivalents seem more frequency functioning as norm in verbal transactions (see Halliday, 1985). As Halliday argues to any metaphorical expression corresponds another, or perhaps more than one, that is literal ... \{ro $\}$ CONGRUENT. When a metaphorical expression can function as norm and is as frequent as its literal realization, we consider that an unmarked metaphor. For example the following sentence is an instance of unmarked metaphorical use.

Metaphorical realization: $<<$ I haven't grasped it $>>$

Literal realization: $\langle\langle$ I haven't understood it $\rangle>$

In the example above, the metaphorical expression is a frequent as its literal realization. But there are other cases of metaphorical expression which do not function as a norm. In these cases the literal realization seems more direct and frequent. Consider the following example:

Metaphorical: <<A flood of protests poured in following the announcement $>>$.

Literal realization: $<<$ A large quantity of protests cam in ... $>>$.

In the above example, the metaphorical expression seems to be marked metaphor. (The examples are taken from Halliday 1985 p. 319). Following this line of thinking, we classified metaphorical expression according to their markedness. As it was mentioned above, out of total number of 125 single word metaphors occurring in our analyzed scientific texts, only 28 metaphors are marked. That is to say only $22 \%$ of single word metaphors used in scientific texttype is marked, while $78 \%$ of single word metaphors are unmarked.

According to our data, in literary text-type, from total number of 34 single word metaphors used in our analyzed text, 21 cases are marked. That is to say $62 \%$ of single word metaphors used in literature texts is marked while only $38 \%$ of single word metaphors used in literary texts are unmarked.

Regarding journalistic text-type, 13 cases of single word metaphorical wording, out of the total number of 14 number of single word metaphors are marked and only one case is unmarked. That is to say $93 \%$ of single-word metaphors are marked, and only $7 \%$ is unmarked.

The difference in degree of markedness of single word metaphorical expressions across different genres is meaningful. Unmarked single word metaphors, which in most cases are abstract word "with concrete origin", have lost their metaphorical force during ages of use, and a have become part of the system of language (see Halliday, 1985). The reason for why words with concrete origin are used to refer to abstract notions is that human beings always use 'knowns' to understand 'new-s' and 'unknown'. This is the natural procedure of cognition. According to cognitive 
psychology, understanding is based on reaching unknowns through knowns. That is to say, understanding takes place on the basis of old information. The same procedure takes place in the natural process of language change. Human beings use an already established and already coined word, with concrete denotative and referential meaning, to talk about more abstract thing 'resembling' to what the word denotatively refers to. We suggest that in the process of evolution of language, human beings who probably could only communicate about concrete subjects became able to talk about more abstract things by using metaphoric expressions, and words gradually have gained new and more additional layers of meaning. Through use, these words have lost their metaphoric force and as Halliday (1985) argues they become the part of the language'.

As it was mentioned above, in scientific text-type $78 \%$ of single words metaphors are unmarked and only $22 \%$ is marked. This is because those scientific texts are 'information oriented', and subject matter should be presented to reader as directly as possible. The producer of scientific text uses unmarked single word metaphors because they are part of the language and he has no other choice but using them.

As far as literary texts are concerned, as it was mentioned above $62 \%$ of single word metaphors in literature texts, seems to us, contributes to the literariness of literature texts by making the process of cognition and comprehension more prolonged. As Shklovsky (1965) argues "the act of perception in art is an end in itself and must be prolonged. In art, it is our experience of the process of construction that counts, not the finished product" (Shklovsky, 1965 quoted in Lotfipour, 1989). As Lotfipour suggests this prolonged voluntary, dynamic, imaginative and goal-oriented search for a meaning contributes to literariness (Lotfipour, 1989). For example consider the following marked use of single word metaphor in a literary text:

Metaphorical expression <<The heart's flower withers at the root $>>$

In the above example the word root is a marked metaphor as a textual/intertextual strategy, brining the image of a tree from outside universe to the universe of the text establishing an intertextual connection between the two universes. The presence of marked metaphors, like the one in the above examples, by making the process of cognition more prolonged contributes to the literariness of literature texts.

As far as the journalistic texts are concerned, $93 \%$ of single word metaphors are marked while only $7 \%$ of the total number of single word metaphors is unmarked. It seems to us that the markedness of individual word (single word) metaphors in journalistic texts contributes to the indirectness of journalistic texts. As we know, it is the characteristic of political texts, journalistic texts included, to say something and to mean something different and more than what is actually said. Most of what the reader of journalistic texts comprehends unconsciously takes place through metaphoric use of language in this text-type. Take, for example, the following sentence from a journalistic text:

$<<$ The queen's staggering wealth and unique tax breaks are always good for stories in the British press. >>

The theme of the article from which the above example is taken, is that the queen should pay her tax. The writer of the text does not directly express his attitude, but through strategic use of some textual strategies imposes his own attitude on the reader. The reader is not consciously aware of what is imposed on him. This is done through strategic use of textual resources. One of these strategies is the use of marked metaphors. In the above example the word staggering denotatively means: 'walking or moving unsteadily.' Metaphorically, the word means $<<$ causing deep shock $>>$. By using this metaphor, the writer suggests that the queen being very rich should pay her tax. The function of marked metaphor in this case is to reinforce the theme of the text indirectly.

We can infer that the same textual /intertextual strategy, in this case single metaphors may contribute to fulfill different functions in different text- types. That is to say, it is not the form, but it is the value of textual /intertextual strategies which distinguishes different genres from each other.

\section{B. Variations in Metaphorical Phrases in Scientific, Literary, and Journalistic Text-types}

As far as metaphorical phrases (i.e. noun phrase, verb phrase, adverb phrase and adjective phrase) are concerned, there is no significant difference between the different text types of our data in terms of frequency of occurrence of these phrases.

In scientific text type, noun phrase (NP) metaphorical elements are mostly used to make the process of understanding more comfortable. For example the metaphorical noun phrase <<tree diagram >> occurring in texts about linguistics, are used firstly by linguists to help the reader to understand subject matter better, by bringing image of tree as a concert object from outside universe to the universe of linguistic texts with the aim of making the process of cognition easier and more possible. In a physiological text, the metaphorical noun phrase $\langle\langle$ free-floating anxiety $\rangle\rangle$ is used to refer to a certain type of disorder by connecting the attribute of floating from concrete and observable universe to more abstract realm of affairs and by doing so the writer helps the reader in the process of cognition .

As far as literary texts are concerned, the presence of NP metaphors, besides contributing to the process of cognition, indirectly reinforces the underlying discoursal theme of the text. The example below illustrates an NP metaphors appearing in Antigone:

Metaphorical expression :<< the long blade of the sun $>>$

Here by using the concrete word 'blade" and establishing a resemblance between it and the sun, the writer strategically helps the reader to transfer what he already knows about blade to his understanding of the text. The producer of text by doing so creates the condition of indeterminacy of intended meaning contributing to the literariness of the text (see Lotfipour, 1989). Besides, by using the above metaphor, the producer of the text indirectly reinforce the 
theme of the text. The text is about cruel murder of a girl named Antigone, and the metaphor is used indirectly to motivate the theme.

In scientific texts, the NP metaphors like in the literary texts are related to the theme of the text. The difference is that in the scientific texts, the reader is conscious about the relationship between the NP - metaphors and the topic (i.e. theme) of the text, while in literature the reader unconsciously creates this connection.

As far as journalistic text-type is concerned, the presence of NP-metaphors contributes to the indirectness of the text. Consider the below example:

.... A drop believed of equal magnitude this year had left $\mathrm{Cuba}<<$ an economic orphan $>>$.

The above metaphorical expression appeared in a journalistic text about the relationship between Castro \& Boris Yeltsin. By using this indifferent way of describing Cuba, the writer indirectly expressed his own attribute toward the topic.

As far as VP metaphors are concerned we found no noticeable difference between these three genres regarding textual manifestations and discourse values.

\section{Clause Complex - Metaphors in the Scientific, Literary, and Journalistic Text-types}

As far as the scientific texts are concerned, the frequency of occurrence of clause complex metaphors is approximately zero in our data. By clause - complex metaphors, we mean those instances of metaphorical expressions which are realized in the textualization process as a sentence. As far as literature texts are concerned, the frequency of occurrence of clause complex metaphors is $22.5 \%$. In the journalistic text type, the frequency of occurrence is $11 \%$. The fact that there is no incidence of occurrence of clause-complex metaphors in scientific texts is meaningful.

As we mentioned before, the scientific texts are information and topic - oriented. We discussed before in discourse production, the topic of the text is broken into sub-topics. These sub -topics are more elaborated in textualization process in the horizontal and vertical dimensions (see Candlin \& Lotfipour, 1982). The sub-topics are determined by the topic (theme) of the text. But the nature of relationship between the sub- topics to topic of the text varies across different genres and is governed and determined by the overall function of the text. In the scientific text- type which is an information oriented text-type, the nature of relationship between topic and subtopics is direct and explicit. So a metaphorical clause complex may hardly appear in this text type. Because in scientific texts what is more important is transferring the information, and what is said has a higher degree of significance compared with how something is said. The clause complex in lexicogrammatical level is the manifestation and actualization of a subtopic. In scientific text type, as it was mentioned above the nature of the relationship between the topic of the text and the subtopics is direct. Metaphorical clause complexes being indirect manifestation of underlying discoursal subtopics have low chance of appearing in scientific texts.

As far as literary texts are concerned, the incidence of frequency of occurrence of metaphorical clause complexes is $22.5 \%$. This higher level of frequency compared with scientific and journalistic texts is meaningful and motivated. In literary texts, like any other texts, the theme or the topic of the text is broken into subtopics but the nature of the relationship of the subtopics to the topic of the text is indirect helping to make the process of understanding and cognition more prolonged. As it was mentioned above, this prolonged search for meaning contributes to literariness of literary texts. We believe that metaphorical clause complexes are indirect surface manifestation of underlying subtopics. In literary texts how something is said is as important as what is said. So metaphorical clause complex, being indirect way of saying and being indirectly related of the topic of the text contributes to indeterminacy and indirectness of literature-texts.

As far as journalistic text-type is concerned the frequency of occurrence is $11 \%$. This frequency is lower than the frequency of occurrence of metaphorical clause-complexes of the literature texts but is higher than the frequency of occurrence in the scientific texts. This finding suggests that the degree of indirectness of journalistic texts is higher than scientific texts but it is lower than literature texts regarding this specific metaphoric wording.

\section{SUMMARY AND CONCLUSION}

In this study after defining `metaphor`as a textual / intertextual strategy bringing `quest images` from the outside real world to the universe of the text, we looked at variations in the textualization of this strategy and its discoursal values across different genres of scientific, literary and journalistic texts. We investigated the textual variations of this strategy in terms of variations in rank dimension across the different genres of the scientific, literary and journalistic texts. We found that these textual variations are meaningful both within a text-type and across different genres.

Regarding variations in rank dimension, we noticed that metaphors mostly appear in 'single word' form in all texttypes. But the value of this strategy is different in different text-types. While in the scientific texts, single word metaphors contribute to ideational function of the text, in the literature and journalistic texts, the single word metaphors by being marked and strategic uses of language, contribute to the way of saying rather than to what is said. That is to say it is textual function rather than ideational function that single word metaphors mainly make contribution to.

As far as metaphorical phrases are concerned, there is again no significant difference across different genres regarding the frequency of occurrence. Here again what distinguishes different genres from each other is the values of the metaphors in different text- types. In literature, metaphorical phrases indirectly reinforce the underlying topic and so 
metaphors are thematically motivated. In journalistic texts, metaphorical phrases contribute to the indirectness of the texts.

As far as clause complex metaphors are concerned, the frequency of occurrence is zero in the scientific text-type. In literature, the frequency of occurrence is $22.5 \%$ and in journalistic text-type the frequency is $1.1 \%$.

We conclude that it is not the form but the discoursal functions of metaphoric wordings which distinguish different text-types from each other.

\section{IMPLICATION OF THE STUDY}

Defining metaphors as one mode of intertextuality, the finding of this study may be of use to the theory of intertextuality. The findings of this study may deepen our understanding of the interrelation between language and power system of the society by looking at why and how language may influence the way people look at the outside realities of the world. The findings of the study are also useful to language pedagogy and language teachers. We believe that the study and teaching of language should not be restricted to vocabulary, grammar, and semantics. In addition to these aspects, pragmatic dimension of language should also be taken into consideration.

\section{REFERENCES}

[1] Bridge C.K and Winkielman, P. (2003). 'What is an unconscious emotion? (The case for unconscious 'Liking")' In cognition and Emotion 17 (2) 181-211

[2] Birch, D. (1991). Language, literature and critical practice, Routledge.11 New Fetter Lane, London.

[3] Burnes, Susan. (2011). "Metaphors in press reports of election: Obama walked on water, but Musharraf was beaten by a knockout", Journal of Pragmatics 43(2011) 2160-2175.

[4] Butt, D. (1988). 'Ideational meaning and existential fabric of a poem' in Fawcett, R.P. \& Young D. J. (eds.) New Developments in Systemic Linguistics Vol. 2 Theory and Applications. Printer Publishers. Pp. 174-218. London.

[5] Candlin, C. and Lotfipour- Saedi, k. (1983). 'Processes of discourse'. Journal of Applied Language Studies 1(2), $103-310$.

[6] Dastjerdi \& Talebinezhad. (2000). `Knowledge of figurative language in reading comprehension and poetry Appreciation` in Iranian journal of applied linguistics vol.4 no.2, pp. 113-130.

[7] Debatin, B. (1997). metaphors and computers. Semiotic Rev. Book 3(1)

[8] Deming, Robert, H. (1986). `Theorizing, Textuality, Intertextuality`. Journal of communication Inquiry 10/3 pp.32-44.

[9] Fairclough, N. (1990). Language and power, London. Longman

[10] Fairclough, N. (2010). Critical Discourse Analysis, Longman UK.

[11] Fowler, R. (1985). 'Power` in van Dijk (ed.) Handbook of Discourse analysis, New York: Academic press.

[12] Geyer- Rayan, H. (1991). Hetroglossia in the poetry of Bertolt Brecht and Tony Harrison' in Willie van Peer (ed.) The Taming of the Text, Rutledge, London

[13] Halliday, M.A.K (1973). Exploration in the function of language, London: Edward Arnold.

[14] Halliday, M.A.K. (1978). Language as social semiotics: the social interpretation of language and meaning. Edward Arnold, London

[15] Halliday, M.A.K. (1985). An introduction to Functional Grammar, London: Edward Arnold.

[16] Haliday` M.A.K \& Hasan` R. (1976). 'Cohesion in English` London: Longman.

[17] Halliday M.A.K. Hasan` R. (1990). Language, Context and Text: Aspects of Language in a Social Semiotic Perspective` Oxford university Press. Oxford

[18] Kingsbury` D.T. and Wagner. G.E (1990). MICROBILOGY. Harwal publishing company, media, Pennsylvania.

[19] Lakoff, G. (1991). `Metaphor and War: the Metaphor system used to justify war in the Gulf (part 1 of 2) `Vietnam Generation Journal \& Newsletter V3.n3.

[20] Lakoff. (1995). 'Metaphor, morality, and politics, or, why conservatives have left liberals in the dust'. Social Research vol.62,no.2

[21] Lakoff .G. (2003). `Metaphor and War again, AlterNet.

[22] Lotfipour- Saedi, K. (1989). `Analyzing Literary discourse: Implication for literary translation. `A paper presented at the first Tabriz University Conference on translation. Iran Tabriz University.

[23] Lotfipour -Saedi, K. (1992). 'Analysing literary discourse: implication for literary translation' in Meta 37-2 p. 389-397.

[24] Lotfipour -Saedi, K. (1993). Lexical Cohesion and Translation Equivalence’. A paper presented at AILA, Amsterdam.

[25] Lotfipour-Saedi, K. (2006). On Discoursal Function of Some Special Textual Strategies in Poetic Texts: Implication for Literary Translation in Meta 51-3 p. 545-550

[26] Lotfipour, Saedi, K. \& Abbasi Bonabi M. (2000). 'Intertextuality as a Textual Strategy: Explorations in its Modes \& Functions' Iranian Journal of Applied Linguistics. Vol.4 No. 2 pp: 79-112.

[27] Lotfipour -Saedi, K. \& Abbasi Bonabi M. (2001). 'Intertextuality as a Textual Strategy: Explorations in its Modes \& Functions' Iranian Journal of Applied Linguistics. Vol.5 No.1 pp. 36-54

[28] Martin, J.P. (1995). 'Text and clause: Fractal resonance' in Text 15(1) pp. 5-42.

[29] Mie-zhen Liao. (1991). 'Metaphor as a Textual strategy in English' in Text Vol.19-(2). de Gruyter

[30] Nucci, Larry, P. (2001). Education in the moral domain. Cambridge University Press, UK.

[31] Otero C.P. (ed.) (2003). Chomsky on Democracy \& Education. Routledge. Falmer

[32] Ortony, A. (1980). 'Metaphor: A Multidimensional problem` in Ortony (ed.) Metaphor \& Thought. Cambridge university press.UK.

[33] Pefister M. (1991). 'How postmodern is intertextuality' in Plett (ed.) Intertextuality Wahter de Guyter.

[34] Perrine, L. (1974). Literature, Sound and Sense vol.1, 2 \& 3. Harcourt Brace Jovanovich, Inc 
[35] Rohrer, T. (1995). 'The Cognitive Science of metaphor from Philosophy' to neuropsychology` rohrer@ darkwing, Uoregon .edu.

[36] Ryan, K. (1991). 'Romeo and Juliet: the language of tragedy' in Willie van Peer (ed.) The Taming of the Text, Routledge, London.

[37] Searle, J. R. (1980). `Metaphor` in Orteny (ed.) Metaphor and thought, Cambridge university press, UK.

[38] Still, Judith\& Worton, Michael. (1990). 'Introduction' in Michael Worton and Judith Still (eds.) Intertextuality: Theory and Practices. Manchester University press pp. 1-44. Manchester

[39] Tendahl, Markus \& Gibbs. (2008). 'Complementary perspectives on metaphor: Cognitive linguistics and relevance theory' Journal of Pragmatics 40 (2008) 1823-1864

[40] Threadgold, Terry. (1987). 'Changing the subject' in Ross Steel \& Terry Threadgold (eds.) Language Topics: Essays in Honor of Michael Halliday vol.2. Amsterdam/ Pladelphia John Benjamins.

Abbassi Bonabi Mina was born in Bonab, Iran in 1968. She majored in English Literature at Tabriz University, Iran in 1992. She got her M.A. on Applied Linguistics from Tabriz University in 1996. Her M.A. thesis was on intertextuality entitled: Intertextuality: Exploration in its functions and modes. She is now a PhD candidate at Tehran Pyam-e- noor University, Iran.

She coauthored a paper on intertextuality entitled: Intertextuality as a Textual Strategy: Explorations in Its Modes and Functions (Part one 2000.Part two 2001) in IJAL. Iran. She also worked on a paper (forthcoming) entitled Metaphor as a textual strategy: Exploration on its modes and functions. Her research interest is on genre analysis, critical linguistics and discourse analysis.

Hemmati Fatemeh was born in Bijar, Iran in 1961. She graduated from Esfahan University (BA in teaching English as a foreign language). She got her MA from Tarbiat Moddarres University, Tehran, Iran. She did her PhD in the same field at University of Essex, England and graduated in 2002. She has published some papers on classroom discourse analysis, writing in English as a foreign language and different methods of teaching writing. She is interested in teaching methods, writing and discourse analysis. 